\title{
Mechanisms of Avian Magnetic Orientation
}

\author{
Joshua Dominic Rizak ${ }^{2}, \mathrm{CHE} \mathrm{Yi}^{1, *}$ \\ (1. Medical College of Soochow University, Suzhou 215000, China;
}

2. Interdisciplinary Program in Neuroscience, Medical College, University of British Columbia, Vancouver, V6T 1Z4, Canada)

\begin{abstract}
Among the most fascinating mysteries of life is the interaction between biological systems and the earth's magnetic field. Although earth's magnetism may have an under appreciated role in biological interpretations, it has been most extensively studied in the processes of avian orientation and migration. Many species of bird are known to have behavioral responses to the earth's and artificial magnetic fields. These responses may be mediated by a number of potential magneto-biochemical processes. The two most commonly investigated include a magnetosensitive magnetite rich region in the upper beak area and a photo/magnetoreception process in the eyes of various bird species. In addition to external magnetic stimuli, recent findings in visually restricted birds have described a hemispherically lateralized interpretation of this information within the brain. Even with these findings, a considerable amount of work is needed to clarify what information is processed and how it is used to create the bird's magnetic compass. This review focuses these recently published findings as a means to assess this intriguing phenomenon.
\end{abstract}

Key words: Avian; Earth's magnetic field; Orientation

\section{鸟类利用地磁场定向的机制}

\author{
Joshua Dominic Rizak ${ }^{2}$ ，车 轶 ${ }^{1, *}$ \\ (1. 苏州大学 医学部, 苏州 215000 , 中国;
}

2. Interdisciplinary Program in Neuroscience, Medical College, University of British Columbia, Vancouver, V6T 1Z4, Canada)

摘要: 地磁场和生物体间的相互作用关系是一个很有趣的未解之迷。虽然对地磁场的生物学作用至今还知之 不多, 不过近来有关鸟类利用地磁场信息定向的研究取得了较大的进展。很多鸟类能够对地磁场和外加磁场信息 做出反应, 这些反应可能通过磁场一生物化学过程介导。对此, 目前有两种被广为接受的解释, 一种认为在鸟喙上 方存在一个磁场信息感受器, 另一种认为通过视觉成像系统感受磁场信息。另外, 最近研究发现磁场信息的感知 分析功能有明显的单侧优势特征。虽然目前有关鸟类利用磁场信息定向的研究取得了很多进展, 但是要想解释并 利用鸟类的磁场定向功能还有很多工作要做。本文结合最近的研究发现对这一有趣的问题进行了综述。

关键词: 鸟类; 地磁场; 定向

中国分类号：Q42; Q144; Q959.7 文献识码：A 文章编号：0254-5853-(2009)02-0221-04

Information from the earth's magnetic field is used by many invertebrate and vertebrate species for orientational and navigational purposes. Many avian species utilize the magnetic field during homing activity, building activity and long distance migration (Wiltschko et al, 2005a). Avian magnetic orientation was first demonstrated 40 years ago in the nocturnal migration of a passerine, the European Robin, Erithacus rubecula (Wiltschko \& Wiltschko, 1972). At present, the magnetic compass has been identified in more than 20 species of birds (Wiltschko et al, 2005a). Although behavioural experiments show that a wide range of birds use the earth's magnetic field as a compass for orientation, the physiological mechanisms enabling birds to sense the earth's magnetic field remains one of the most fascinating unresolved mysteries in biology. Recently, interdisciplinary interactions between theoretical biophysics, neuroscience, molecular biology, and behavioural biology have generated considerable advances in this field, offering new insights into the physiological mechanisms that enable birds to use magnetic fields for orientation. 


\section{The behavioral research model of avian}

\section{magnetic orientation}

Captive migratory birds were observed to prefer their natural migratory direction during the migratory season. However, when the North direction of the ambient magnetic field was shifted, the birds changed the direction of their headings accordingly. This indicated that birds located their migratory direction with the help of the magnetic field (Wiltschko et al, 2005a). Numerous behavioural experiments show that many species of birds use the earth's magnetic field as a compass for orientation, however direct evidence from conditioning experiments has proved elusive (Wiltschko et al, 2005a). Until recently, the only two successful attempts of operant conditioning in birds to magnetic stimuli (Mora et al, 2004) involved magnetic anomalies rather than changes in magnetic direction. Freire et al (2005) used the young domestic chick's motivation to locate a hidden social stimulus to demonstrate the first conditioned magnetic compass response in birds. Additionally, Freire et al (2005) had shown that the chick's ability to orient using magnetic cues has been retained after thousands of years of domestication.

\section{The magnetoreceptive mechanisms of}

\section{avian magnetic orientation}

Many avian species seem to have two separate magnetodetection senses: one based on magnetite near the beak and the other based on light-dependent radical-pair processes in the bird's eyes. These two hypotheses favoured in the current discussion on magnetoreception assume different primary processes involved in the physical mechanisms. The magnetite hypothesis proposes that magnetic input is mediated by particles of magnetite and magnetoreception occurs in the upper beak area of the avian species (Yorke, 1979; Mora et al, 2004). Whereas, the light-dependency of the avian magnetic compass suggests that magnetic input is mediated by magnetically sensitive chemical processes involving specialized photo pigments (Maeda et al, 2008). In consideration of the diversity within avian groups, this phenomenon may be a common unidentified physiological aspect for many other birds, which both have and use these magnetoreception mechanisms.

\subsection{Magnetite $\left(\mathrm{Fe}_{3} \mathrm{O}_{4}\right)$-based magnetoreception hypothesis}

The current hypothesis describing pigeon homing suggests pigeons can use the earth's magnetic field to return to its loft after traveling great distances (Mora et al, 2004). This hypothesis is based on the magnetic effects on pigeon orientation, where indirect evidence provides potential descriptors for a magnetic 'map'. Magnetoreception (probably magnetite-based) occurs in the upper beak area of the pigeon potentially enabling the animal to distinguish the magnetic stimuli. Cordula V. Mora and Michael M. Walker demonstrated that homing pigeons (Columba livia) can discriminate between the presence and absence of a magnetic anomaly in a conditioned choice experiment (Mora et al, 2004). This discrimination can be impaired by the attachment of a magnet to the cere, local anaesthesia of the upper beak area, or the bilateral cross-section of the ophthalmic branch of the trigeminal nerve (Mora et al, 2004, Fleissner \& Stahl, 2007 ). In addition, a short, strong magnetic pulse could cause migratory birds to change their headings from their normal migratory direction to an easterly direction in both the spring and autumn (Wiltschko et al, 2002). Migratory Australian Silvereyes, Zosterops lateralis, were subjected to a magnetic pulse and their subsequent response under different magnetic conditions was tested. In the local geomagnetic field, the birds preferred easterly headings as expected, and when the horizontal component of the magnetic field was shifted $90^{\circ}$ anti-clockwise, they altered their headings northwards to align with the shift in magnetic field direction. In a field with the vertical component inverted, the birds reversed their headings to westwards, indicating that their directional orientation was controlled by a normal inclination compass. The magnetite-based receptors seem to mediate this compass, utilizing the magnetic 'map'-information to determine position, and when affected by a magnetic pulse, the birds respond to false positional information causing them to change their course (Wiltschko et al, 2002).

\subsection{Photoreceptor-based magnetoreception hypothe-} sis

The light-dependency of the avian magnetic compass was first studied in the 1990s. The photoreceptor-based magnetoreception hypothesis proposes that magnetic information is transmitted to the nervous system through the light induced product of magnetically sensitive radical pair reactions in specialized photoreceptors (Mouritsen et al, 2004). Magnetic orientation in migratory birds has been shown to be based on radical pair processes and to require light from the short wavelength part of the spectrum up to 565 
$\mathrm{nm}$ green wavelength and to be strongly lateralized (Liedvogel et al, 2007). Under dim red light (645 nm wavelength), Australian silvereyes and European robins showed a westernly tendency that did not change between spring and autumn (Wiltschko et al, 2005b). A thorough analysis revealed that green light dependent orientation did not involve the inclination compass, but was a response based on the polarity of the magnetic field (Muheim et al, 2006; Wiltschko et al, 2005b). In contrast to the orientation observed under short wavelength light, the orientation under red light could be disrupted by local anaesthesia of the upper beak where magnetoreception is located, indicating that it is controlled by magnetite-based receptors (Johnsen \& Lohmann, 2005). Additionally, similar findings have been observed between the magnetic response under dim red light and the response in total darkness, suggesting that these two responses may be identical (Johnsen \& Lohmann, 2005; Wiltschko et al, 2005b). Together, this indicated that the observed "fixed direction" response under dim red light is fundamentally different from the normal compass orientation seen during green light exposure, which is dependent on radical pair processes (Johnsen \& Lohmann, 2005; Wiltschko et al 2005b).

Potentially, photopigments can mediate the light-dependency response witnessed in the avian magnetic compass. Three main lines of evidence support this hypothesis. (1) Photopigments, such as retinal in the opsin-family of photoreceptors, undergo a conformational change upon light absorption triggering the reaction cascade underlying normal visual photoreception (Liedvogel et al, 2007; Wiltschko et al, 2005b). (2) Other photopigments, such as chlorophyll or flavin molecules, use light energy to transfer electrons to nearby molecules, thereby generating a pair of molecules with unpaired electrons, a so-called radical pair. Radicals are very reactive molecules and their presence quickly leads to further reaction steps, product formations and biochemical signal transduction. Under certain conditions, magnetic fields can influence the speed or yield with which radical-pair products are formed (Liedvogel1 et al, 2007; Wiltschko et al 2005b). (3) Recent findings in the fruit fly, Drosophila melanogaster, have established an evolutionary precedence that involves short wavelength UV-A /blue light $(<420 \mathrm{~nm})$ photoreception in the magnetosensitive behaviour of a Cryptochrome (Cry) null mutant (Gegear et al, 2008). Although it is not clear how the physical mechanisms involving the interplay between the magnetic and electric fields influence the quantum behaviour of specific biomolecules transducing the geomagnetic information internally and that resolution of this problem may need further evaluation of unanswered physical questions, the involvement of photoreception in the avian magnetic process is gaining momentum as an adequate hypothesis to address this phenomenon.

Interestingly, this photoreceptor mediated orientation is maintained when the European Robins were restricted to use of their right eye (Liedvogell et al, 2007). However, when the birds were restricted to left eye use, this response was not observed. This has been interpreted as the possible lateralization of the perception mechanisms for magnetic cues in favour of the right eye. Wiltschko et al (2007) showed that in a magnetic field with North shifted by $90^{\circ}$, chicks using their right eye oriented according to magnetic cues, whereas chicks using the left eye did not and continued to prefer the original direction. Analysis of the times taken to respond to magnetic cues indicated longer latencies in the chicks using their left eye (Rogers et al, 2008). This suggested a possible conflict between different cues and that the different behaviour seen in chicks using their left eye might not simply be a matter of a right eye-left hemisphere specialization in detection of magnetic directions, and more a matter of hemispheric specializations needed for attending to specific types of cues. Despite these interpretations, the physiological mechanisms that are involved in the hemispheric specializations are not clearly understood.

Together these findings suggest that the magnetic compass orientation in night-migratory birds may be influenced by the availability of light with specific wavelengths as the reception of magnetic compass information is light-dependent, and that the ability to orient with the use of directional cues from the geomagnetic field is hemispherically lateralized in some avian species.

\section{Summary}

Among the most exciting recent findings describing the potential nature of the avian model of magnetic responses include: (1) The behavioural responses of chicks experiencing oscillating magnetic fields and the finding that lateralization of avian magnetic orientation occurs. (2) The occurrence of light-dependency in the avian magnetic compass and the existence of putative magnetosensory molecules, such as cryptochromes, in the eyes of migratory birds. (3) A magnetoreception and 
a magnetosensory cluster of magnetite in the upper beak area. Though these findings have important implications for the physiological mechanism of how birds sense the earth's magnetic field, many crucial questions remain unanswered. For example, how magnetic information is

\section{References:}

Fleissner G, Stahl B. 2007. A novel concept of Fe-mineral-based magnetoreception: histological and physicochemical data from the upper beak of homing pigeons[J]. Naturwissenschaften, 94 (8): 631-642.

Freire R, Munro UH, Rogers LJ, Wiltschko R. 2005. Chicken orient using a magnetic compass[J]. Curr Biol, 15(16): 620 -621.

Gegear RJ, Casselman A, Waddell S, Reppert SM. 2008. Cryptochrome mediates light-dependent magnetosensitivity in Drosophila. Nature[J], 454(7207): 1014-1018.

Johnsen S, Lohmann KJ. 2005. The physics and neurobiology of magnetoreceptive[J]. Nature Review Neuroscience, 6(9): 703-712.

Liedvogel M, Feenders G, Wada K, Troje NF. 2007. Lateralized activation of Cluster $\mathrm{N}$ in the brains of migratory songbirds $[\mathrm{J}]$. Eur J Neurosci, 25(4): 1166-1173.

Maeda K, Henbest KB. 2008. Chemical compass model of avian magnetoreception[J]. Nature, 453(7193): 387-90.

Mora CV, Davison M, Wild JM, Walker MM. 2004. Magnetoreception and its trigeminal mediation in the homing pigeon[J]. Nature, 432(7016): 508-511.

Mouritsen H, Janssen-Bienhold U, Liedvogel M, Feenders G, Stalleicken J, Dirks P, Weiler R. 2004. Cryptochromes and neuronal-activity markers colocalize in the retina of migratory birds during magnetic orientation[J]. Proc Natl Acad Sci USA, 101 (39): 14294-14299. transmitted through the nervous system and represented in the brain and whether birds can use magnetic information under specific environmental conditions to mediate behavioural responses?

Muheim R, Phillips JB, Akesson S. 2006. Polarized light cues underlie compass calibration in migratory songbirds $[\mathrm{J}]$. Science, 313(5788): 837-839.

Rogers LJ, Munro U, Freire R, Wiltschko R, Wiltschko W. 2008. Lateralized response of chicks to magnetic cues[J]. Behavioural Brain Research, 186 (1): 66-71.

Wiltschko R, Wiltschko W. 2005a. Magnetic orientation and magnetoreception in birds and other animals[J]. J Comp Physiol A, 191 (8): 675--693.

Wiltschko R, Ritz T, Wiltschko W. 2005b. Two different types of light-dependent responses to magnetic fields in birds[J]. Current Biology, 15 (16): 1518-1523.

Wiltschko W, Wiltschko R. 1972. Magnetic compass of European robins[J]. Science, 176 (4030): 62-64.

Wiltschko W, Munro U, Wiltschko R, Kirschvink JL. 2002. Magnetite-based magnetoreception in birds: the effect of a biasing field and a pulse on migratory behavior[J]. J Exp Biol, 205(19): 3031-3037.

Wiltschko W, Freire R, Munro U, Ritz T, Rogers L, Thalau P, Wiltschko R. 2007. The magnetic compass of domestic chickens, Gallus gallus[J]. The Journal of Experimental Biology, 210 (13): 2300-2310.

Yorke ED. 1979. A possible magnetic transducer in birds [J]. $J$ Theor Biol, 77(1): 101-105. 